\title{
Research on the Approaches to Construct "Belt and Road" in Colleges and Universities
}

\author{
Lei Shi, Ting Jiang* \\ College of Marxism, Xi'an University of Science and Technology, Xi'an, P. R. China \\ Email address: \\ 1016986303@qq.com (Lei Shi),jiangt0126@126.com (Ting Jiang) \\ ${ }^{*}$ Corresponding author
}

\section{To cite this article:}

Lei Shi, Ting Jiang. Research on the Approaches to Construct "Belt and Road" in Colleges and Universities. Higher Education Research. Vol. 5, No. 5, 2020, pp. 174-180. doi: 10.11648/j.her.20200505.12

Received: July 30, 2020; Accepted: August 17, 2020; Published: September 10, 2020

\begin{abstract}
The report of the Nineteenth National Congress of the Party clearly states that we will move faster to build Chinese universities into world-class universities and develop world-class disciplines as we work to bring out the full potential of higher education. Under the background of "Belt and Road" construction, higher education is a "connecting heart bridge" for communication and cooperation between countries, and also a "adhesive" for co-construction and sharing. It has unique and irreplaceable advantages in the construction of "Belt and Road". The construction of "B\&R" provides a broader space for the development of higher education and puts forward new requirements. In the face of the opportunities and challenges of "B\&R", colleges and universities should take the initiative and push forward pragmatically, especially in the areas that are important nodes, and should speed up their own development in striving to serve the national strategy. By analyzing "three major challenges" of foreign exchange and cooperation in colleges and universities under the strategy of "B\&R ", this paper finds out the" five major paths "for colleges and universities to help" B\&R ", and analyzes them in detail in order to promote the international development of higher education in colleges and universities and to help the construction of "B\&R".
\end{abstract}

Keywords: B\&R, Higher Education, Pathways, Exploration

\section{Introduction}

\subsection{The Overall Evolution of the B\&R Strategy}

In 2013, President Xi Jinping put forward the idea of building the "Silk Road Economic Belt" and "21st Century Maritime Silk Road "(referred to as "B\&R") [1]. The introduction of the "B\&R" strategy is the result of China's own cognitive changes to promote the realization of Chinese Dream. The strategy of "B\&R" is not only the need for China to continue to expand and deepen its opening to the outside world, but also to strengthen mutual benefit and cooperation with the countries of Asia, Europe and Africa. By the end of August 2019, China had signed 195"B\&R "cooperation documents with 136 countries and 30 international organizations road circle of friends throughout Asia, Africa, Europe, Oceania and Latin America. The findings are that "B\&R" transport investments favor development in larger urban districts near trade hubs [2].

With the continuous improvement of China's international status and influence, General Secretary Xi Jinping proposed the "Belt and Road" economic development strategy [3]. Hand in hand with multi-country development strategy to achieve accurate docking. China will put the "B\&R" strategy in the next 8 to 10 years of foreign policy. "B\&R" is not a Chinese solo, but a chorus from countries along the route. In China's cooperation with countries along the route, China will grasp a principle: only responders and supporters, not leaders and contractors. On this basis, according to different types of countries, pursue different foreign policies [4]. The construction of "B\&R" not only promotes the realization of Chinese Dream, but also embodies the world responsibility of China's rise, and is also conducive to the realization of the purpose of United Nations peace and development. Under the strategy of the $\mathrm{B} \& \mathrm{R}$, the communication and communication between our country and the countries along the route will become more comprehensive. from politics, economy to culture and education, every aspect of education will reach a new height of history. this strategy also brings new opportunities and challenges to higher education in China. 


\subsection{The Relationship Between B\&R and Higher Education}

\subsection{1. "B\&R" Brings Opportunities for the Development of Higher Education}

The development of higher education is facing new development opportunities. The "B\&R" initiative, as an important concept for China to expand and deepen its opening to the outside world, is bound to bring new development opportunities for the internationalization of higher education in China. Some scholars believe that the "B\&R" initiative has brought development opportunities for deepening the reform of higher education in China, making up for the shortage of higher education resources, establishing the concept of international education, expanding the international education market, promoting the integration of industry and education, and promoting the development of professional talents at home and abroad. The "B\&R" initiative provides a new development for China to train international talents, promote cooperation in running schools and expand student employment and practice space Opportunities. From the level of macro, the "B\&R" initiative will have a certain impact on the relevant educational internationalization policies (such as foreign students, the policy of Sino-foreign cooperation in running schools, the policy of running schools abroad, etc.) in the process of the internationalization of higher education in China. From the level of macro, the "B\&R" initiative will have a certain impact on the enrollment policy, talent training, curriculum system, teacher structure, management mechanism of colleges and universities in China, and objectively promote the optimization and adjustment of colleges and universities to realize their own development. The "B\&R" Strategy has brought unprecedented opportunities for the development of higher education in China.

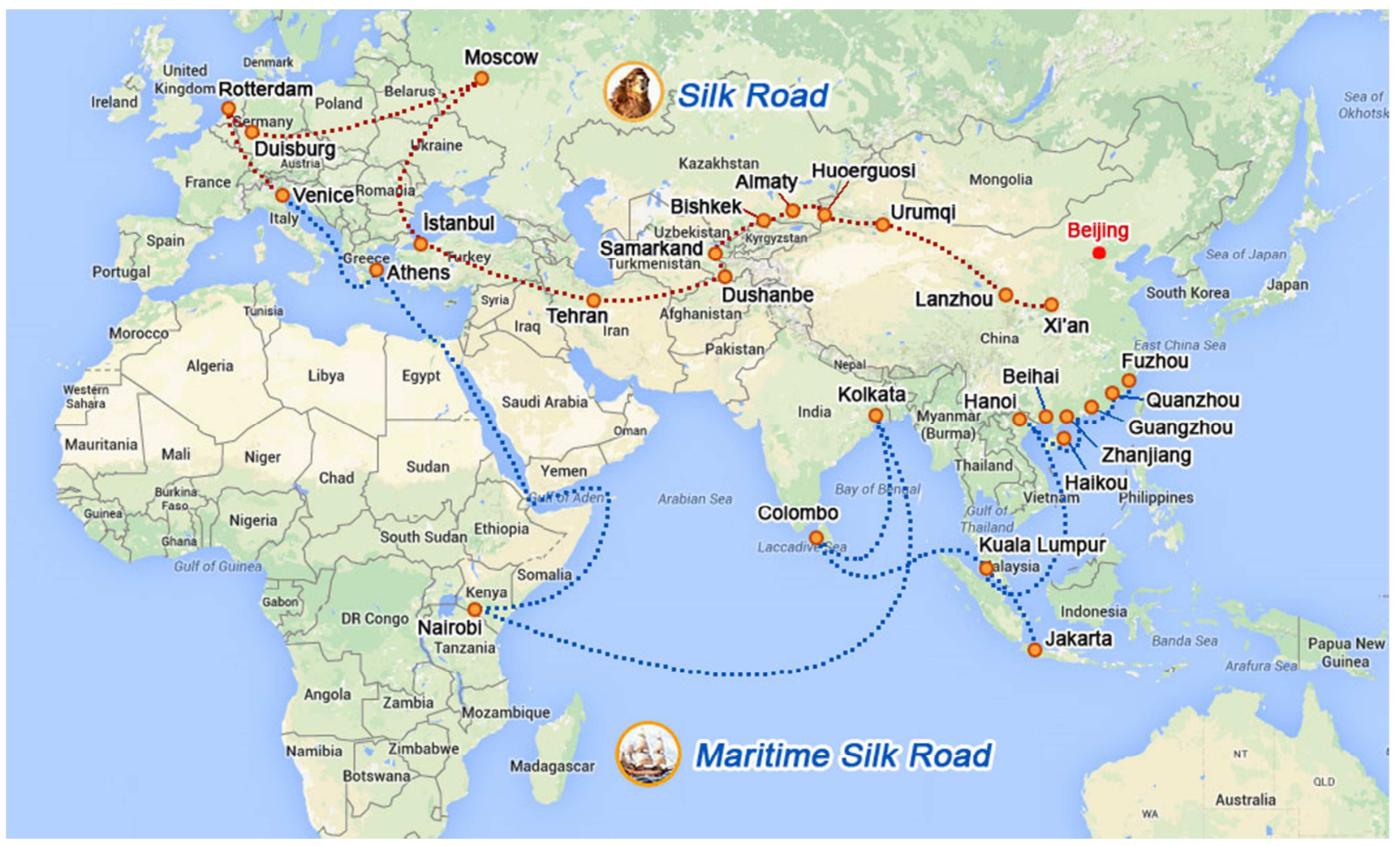

Figure 1. Countries and cities along the " $B \& R$ ".

\subsubsection{Challenges to the Development of Higher Education Under the B\& R Strategy}

The B\&R initiative brings development opportunities for the internationalization of higher education, but also makes it face new challenges. First of all, the "B\&R" initiative spans Asia, Europe and Africa, involving different races, religions, cultures and polities, coupled with the increasingly complex international political environment, the political situation of some countries and regions along the route is unstable, the economic development is backward, the social order is chaotic, and the risk of educational exchange and cooperation is increased. Secondly, familiar with the national conditions along the lack of kindness. With the implementation of "B\&R" national strategy, the cultivation of international talents in colleges and universities has encountered new challenges. First, the countries along the route are rich in official languages. Second, the economic development of the countries along the route is uneven, both economically developed countries and extremely backward countries, most of which are developing countries, with significant differences in the degree of marketization; Third, the situation in some countries along the route is tense, the security environment is complex and changeable, and the factors of disharmony, insecurity and instability exist; Fourth, the ideological, ethnic, cultural and ethnic differences of the countries along the route are obvious, among which there are many kinds of religions. 
In the face of such a complex and dynamic political, economic and cultural environment, it is possible to master both business and international rules. Only by grasping the local political, economic, religious and cultural customs can we strengthen mutual trust and carry out deep-level cooperation. However, at present, such talents are relatively scarce. Therefore, the cultivation of international talents who know the national conditions of the countries along the route has become the key to promote the effective implementation of the "B\&R" strategy. Finally, the quality of higher education in China is not competitive in the international market, the development model of higher education is single, the phenomenon of homogenization is serious, and objectively brings some challenges to its own development.

\section{2. "Three Major Challenges" in Colleges and Universities under the Construction of "B\&R"}

\subsection{Demand for Complex Talents}

The Outline of the National Medium- and Long-term Education Reform and Development Plan (2010-2020) proposes to train a large number of international talents with international vision, knowledge of international rules, ability to participate in international affairs and international competition. In order to realize the cultural blending, public diplomacy and media cooperation among the countries along the route, complex talents are needed, complex talents, familiar with the national policies and conditions of various countries, proficient in many languages, understand the cultures of various places, and have professional knowledge.

This same technology can make an enormous difference in human resource and talent management enabling individuals to market their skillsets and organizations to describe their job requirements down to a granular level of detail in the hopes that searches, optimization algorithms, and simple recommendation engines can guide them towards an optimal decision for talent management, the right person in the right job at the right time [5].

First of all, language is the basis for all communication, and it is the link to enhance national interaction, cultural exchange, policy exchange and cohesion. The "B\&R" involves many countries, More than 50 official languages, together with nearly 200 national or tribal languages, are currently only 20 language courses offered in colleges and universities in China. The shortage of language translation talents can not meet the strategic needs of "B\&R ". Therefore, higher education needs to strengthen the training of non-common language talents. Secondly, most of the countries along the "B\&R" are multicultural gathering areas, and cultural problems will arise in the process of cultural exchanges and economic and trade cooperation, which requires us to train a group of talents with multicultural cognition. Through these talents overseas cooperation and exchange, carry out other activities. Finally, the familiarity, the talent demand of national policy, national conditions and historical changes. Under the "B\&R" strategy, fully understanding the culture, policy and national conditions of other countries can avoid civil, strategic and political conflicts with other countries. Therefore, we should strengthen the training of complex talents, at the same time give play to the important role of cross-border ethnic Chinese and overseas Chinese, with the help of these people's understanding of local customs, various policies and social conditions, so as to promote the further implementation of the "B\&R" strategy.

Many colleges and universities in China have established stable and friendly cooperative relations with universities and scientific research institutions in more than 20 countries and regions, such as the United States, the United Kingdom, Russia, Japan, the Netherlands and Australia, but under the "B\&R" strategy, it puts forward new challenges for the foreign affairs service ability of colleges and universities. Because the countries along the $\mathrm{B} \& \mathrm{R}$ have their own unique language, traditional habits, festivals, religious beliefs and taboos, how to promote cultural exchanges and cooperation among countries under the premise of respecting the cultural traditions of the countries along the B\&R, so that China's higher education can "go out" and cultivate complex people who can serve the construction of B\&R is the key, is also one of the significance of colleges and universities to help the "B\&R" construction.

\subsection{Demand for Educational Resources and Structures}

As a link of international exchange, the modern Silk Road is open to any country and region. Under the background of "B\&R" strategy, China's higher education should be developed by strength, and the promotion of strength needs strong financial resources as the support. China's economy continues to develop, becoming the world's second largest economy. However, the conditions of running schools in China lag behind the economically developed areas along the B\&R. How to reasonably use limited basic resources and improve the efficiency of the use of educational funds is a practical problem that must be solved in China's higher education to meet the strategic challenges of "B\&R" in China. Ministry of Education statistics show that in the past five years, the number of foreign students coming to China From 328330 to 442773 , The growth rate was $34.86 \%$, Among them, the number of students coming to China from countries along the "B\&R" has increased from 142027 to 223998 , The growth rate was 57.72 per cent, Higher than the annual growth rate of foreign students in China [6]. 2016, China's Ministry of Education in "Promoting the Co-Construction of 'B\&R' Education Action": the next three years, China sends 2500 foreign students each year to the countries along the route; For the next five years, Build 10 overseas science and education bases, Each year, 10,000 new students from countries along the route are funded to study or study in China. Facing a large number of Chinese Foreign students, need more professional teachers, teaching resources, need to adjust the teaching structure in time.

Joshua J. Thoms introduced that some resources and support 
are critical to establish or expand the use of open educational resource in courses in the US [7]. For a long time, in the aspect of foreign exchange, colleges and universities have carried out different levels of cooperation with famous overseas universities, academic organizations, research institutions and enterprises and institutions in line with the principle of extensive exchange and expansion of cooperation, and have also made a series of achievements. It has played a certain role in improving the comprehensive quality of teachers and students and the level of internationalization of schools.

Colleges and universities need to establish an excellent teaching staff and professional education team. Because foreign affairs are very complicated and complicated, it is necessary to face international communication and professional cooperation with foreign language advantages and specialties. Many colleges and universities are responsible for international exchanges and cooperation are the International Exchange and Cooperation Office, the Institute of International Education, Hong Kong, Macao and Taiwan Affairs Office. The heads of the International Exchange and Cooperation Service, the Institute of International Education, the Hong Kong, Macao and Taiwan Affairs Office of many colleges and universities and their staff are almost all administrative staff, so most of them will lack the background of professional foreign language and learning overseas, professional knowledge in education and foreign-related education are not conducive to international exchanges and cooperation.

\subsection{Demand for Disciplines}

The construction of "B\&R" is focused on "culture, tourism, trade, finance, transportation and infrastructure ", which requires a large number of talents in the fields of economy and trade, infrastructure construction, transportation, information, language and tourism. Taking Shaanxi Province as an example, due to the influence of economy, region and industry in running schools at the beginning, the development over the years has formed the situation of "strong engineering, weak science and lack of liberal arts ". The existing dominant majors are mainly concentrated in engineering fields such as machinery, aviation, electronics and chemical industry, which can not meet the needs of" B\&R "construction.

At the same time, through the analysis of Internet big data at home and abroad, it is found that the demand of language subject ranks first in domestic media and Internet users, and fourth in national media and Internet users. Among them, in addition to English, Arabic and other widely used languages, Turkish, Bengali, Persian and so on are also highly concerned by the media and Internet users. The media and netizens at home and abroad generally believe that "language interworking" is the basis of "B\&R" interconnection. With the further development of "B\&R" construction, language talents, especially small languages, are very short, and language services can be provided. It is urgent and necessary to strengthen the language capacity building of B\&R.

\section{3. "Five Major Paths" for the Internationalization of Universities}

\subsection{School-enterprise Cooperation to Train National Talents to Help "B\&R" Construction}

Close cooperation between enterprises and schools can achieve the "multi-win" effect of complementary advantages, mutual exchange of resources, benefit sharing and common development.

Some scholars believe it is important to establish of the orientation direction and goal of talents cultivation, and optimize training plans, eventually to build the cultivation model with strong operability for the application talents by the diversification school-enterprise cooperation. [8] In the enterprise aspect, the human resource reserve and the potential human resource have obtained the recognition to the enterprise culture; in the school aspect, has established the supply and demand docking specialized and the stable practice base, has perfected the practice teaching condition, has improved the teaching quality. From the student aspect, the student has the goal of learning, improves the skill level and the work ability in practice, its specialized skill and the future job position match more; from the enterprise aspect, through the cooperation, The enterprise obtains the stable skilled operation talented person and the high skilled talented person. From the school point of view, the quality of running a school has been improved, and its social and economic benefits have been improved. Under the B\&R strategy, we should persist in establishing the operational mechanism of joint training and management of schools and enterprises, expand the educational resources of the industry, and benefit from overseas enterprises by strengthening cooperation with overseas enterprises. Gradually realize the strategic goal of "education going out".

The Belt and Road Initiative will involve huge amount of projects, so China should justify the fairness and transparency of these project [9]. The cooperation between school and enterprise needs to strengthen the construction of practical teaching platform, construct the team of practical teaching tutors, renew and enrich the content of practical teaching, strengthen the construction of evaluation mechanism of practical teaching effect, perfect the quality guarantee system of practical teaching, actively integrate all aspects of social resources, construct practical teaching force and long-term mechanism, and strengthen practical teaching in order to realize the training goal of overseas students with high professional level.

Through the above analysis, we can see that the enterprise not only requires foreign students to have a higher level of professional knowledge and practical ability, but also requires foreign students to have a strong cross-cultural communication ability. Therefore, we must adhere to the ability as the most important, by optimizing the knowledge structure of foreign students, enrich their social practice content, to strengthen the cultivation of their comprehensive ability. 


\subsection{Construction of Science and Technology Innovation Education Platform to Help "B\&R" Construction}

Scientific and technological cooperation plays an important role in the B\&R initiative, and the international technology transfer fully embodies this new spirit of cooperation. China is the world's second largest economy and an important investor in B\&R. Colleges and universities should deepen their understanding of the "B\&R" initiative, implement the spirit of the Silk Road, adhere to the high-level concept of the "B\&R" initiative, and take into account the established rules of the international technology trading market and the position of equality, harmony and common development in China [10].

"Shaanxi Province B\&R Construction Action Plan 2019" to promote the construction of five major centers, the third point to focus on the construction of science and technology education center. Promote universities, scientific research institutions and enterprises in the province to cooperate with foreign innovation institutions to set up innovation cooperation platforms and carry out transnational joint R \& D and technology transfer. We will continue to promote the implementation of the "B\&R" Memorandum of International Cooperation on Educational Action signed with the Ministry of Education, further expand the opening up of education throughout the province, and build a Silk Road vocational education base.

In a word, colleges and universities should carry out scientific and technological innovation, accumulate scientific and technological advantages, and transform scientific and technological research achievements into practical technologies in a timely manner. For example, through the overseas branch of the enterprise or overseas branch structure to the "B\&R" countries to develop education and economic undertakings.

\subsection{Join the University Alliance to Help "B\&R" Construction}

UNESCO's book "Learning to Live" states:" The participation of all countries at different levels of development in education, together with the completion of educational collaboration, is beneficial to all participating countries."

Isabel Estrada and others believe that different combinations of dissimilarities are likely to trigger particular coordination and cooperation patterns in University alliances, eliciting different outcomes on both technological and relational levels [11]. Under the guidance of $B \& R$, in order to promote talent training, we should also learn to share. On the one hand, we can work together to establish a university alliance along the B\&R area. On October 17,2015,46 Chinese and foreign universities, including Fudan University, Beijing normal University, Lanzhou University, Ural National University of Economics in Russia and Kaoqing University in Korea, jointly set up the "B\&R" University Strategic Alliance in Dunhuang, Gansu Province, to explore Cultivate high-quality talents with international vision and new mechanism of transnational training and cross-border flow. At present, there are "Silk Road University Alliance "," New Silk
Road University Alliance" and other alliances in China. On this basis, we can construct diversified university alliances oriented by field, specialty and regional development needs to serve the contents of talent training, talent exchange, cultural communication and scientific research cooperation, and provide a platform for cooperation and exchange between universities or regions. As a community of education, the "B\&R" University Alliance plays a holistic role, such as high-level consultations, project implementation and retention. In the aspects of student training and management, the university alliance will build a lot of platforms, open up more channels, constantly absorb new members, and strive to create a comprehensive and open high-end alliance with all-round, cross-domain and multi-subject. In order to build a high-end alliance of deep communication and realize mutual knowledge and mutual trust, mutual help and mutual assistance, mutual learning and mutual learning among the members of the alliance, the "B\&R" university alliance needs to make efforts on the talent training mechanism, the joint training system and the discipline construction platform, and to deepen the academic dialogue and exchange and the promotion of culture.

\subsection{Develop the Industry and Education Integration Mechanism to Help "B\& R" Construction}

On December 19, 2017, the State Council issued a number of opinions on deepening the integration of industry and education, which promoted the integration of education and industry in order to improve the quality of human resources in an all-round way.

It is found that integration of science, education and industry based on higher education establishments is a multi-level process [12]. To promote the integration of industry and education, broaden the ways for enterprises to participate in running schools, guide enterprises to come in with capital, technology and management, guide enterprises to participate in teaching design, curriculum design and practice training, improve the system of students' practice training in enterprises, expand the co-construction model of enterprises and schools' productive training bases, promote collaborative innovation and strengthen cooperation with enterprises and research institutes. Develop scientific research technology to tackle key problems, accelerate the application of basic research results to industrial technology transformation. Through a series of school-enterprise cooperation measures to carry out collaborative education, efforts in personnel training, scientific research and other aspects of the integration of industry and education to carry out more in-depth, practical, practical results [13]. For example, in 2017, Hohai University actively responded to the national "B\&R" initiative, made full use of its own discipline advantages, actively docked the needs of the actual development of the country, industry and enterprises, launched the "B\&R" water strategic alliance, and with more than 40 enterprises and institutions, universities and scientific research institutes in many countries to build services under "B\&R" initiative. Discuss the cooperation platform of government, industry, education and research. 


\subsection{Strengthen Cultural Exchange and Communication to Help the Construction of "B\&R"}

Education is closely related to culture. One of the important functions of education is to promote cultural inheritance and innovation. With five thousand years of history and culture, China has carried out educational and cultural exchanges with countries and regions along the "B\&R" in all directions, so that the world can understand China's education and culture, let China's education and culture go to the world, and promote the great development and prosperity of China's educational culture [14]. First, build a platform for cooperation and exchange, and pave the way for promoting educational exchanges between higher education and countries and regions along the $B \& R$. Second, promote the exchange of personnel between China and countries and regions along the "B\&R ", carry out regular exchanges of scholars and dispatch. Teachers go to countries along the B\&R to study and teach. Third, carry out cultural activities year, activity month and activity week for the countries along the route, and carry out regular exchanges with the countries along the route, such as seminars, visits and visits, so as to enhance mutual understanding and realize the exchange of ideas, cultural exchanges and the sharing of experiences. Fourth, make good use of Confucius Institute and other overseas talent training platform. Through a series of exchanges and cooperation, spread the Chinese voice, show the image of China, promote China's development.

In a word, we can promote the culture of wide consultation and joint contribution through these ways [15]. The friendship of the country lies in the blind date of the people, and the blind date of the people promotes the success of the matter. Through international academic forums, academic exchanges and other activities to face and solve the problems of resources, environment, ecology and so on. In the process of communication, we can promote mutual understanding, mutual trust and cooperation among the citizens of the countries along the route, promote the diplomacy of higher education, forum diplomacy, promote university cooperation, and deepen the humanistic exchange among countries through various academic exchanges and cooperation, so as to buffer cultural conflicts and enhance cultural understanding among countries, thus providing a more effective path for cooperation in higher education

\section{Conclusion}

Colleges and universities should actively promote educational cooperation with countries along the "B\&R" route, strengthen personnel training, innovate cooperation mechanisms, promote international collaborative innovation, and speed up the process of running schools internationally. Promote the "B\&R" of school education action to the depth of development. Under the strategy of "B\&R ", colleges and universities are faced with" three challenges ". Through the "five major paths ", that is, cooperation between schools and enterprises to train national talents, build scientific and technological innovation platform, join university alliance, develop integration mechanism of industry and education, and strengthen cultural exchange and communication, finally realize the development of their own higher education and help the construction of " B\&R".

\section{Acknowledgements}

We thank the academic editors and anonymous reviewers for their kind suggestions and valuable comments. This research was supported by the Soft Science Project of Shaanxi Provincial Science and Technology Department (No. 2007KR82), Key Research Project of Teaching Reform in Shaanxi Colleges and Universities (No. 17BG016), and Scientific Research Project of Higher Education of Shaanxi Institute of Higher Education (No. XGH19033, XGH17009).

\section{References}

[1] Xi, J. P. (2017) Secure a Decisive Victory in Building a Moderately Prosperous Society in All Respects and Strive for the Great Success of Socialism with Chinese Characteristics for a New Era-Delivered at the 19th National Congress of the Communist Party of China. People's Daily, 2017-10-28.

[2] Lall S. V. Lebrand M. (2020). Who wins, who loses? Understanding the spatially differentiated effects of the belt and road initiative. Journal of Development Economics, Volume 146.

[3] Li, L. (2020) Views of the Challenges and Opportunities of International Exchange and Cooperation Facing Universities and Colleges in the West under the Background of the Belt and Road Initiative. Voice of the Publisher, 6, 40-46.

[4] Xue L. (2016): The arrival of "The Belt and Road" and "Asia-Europe World" (China Social Sciences Press, China), pp. 99.

[5] Kristin C. Saling, Michael D (2020). Leveraging People Analytics for an Adaptive Complex Talent Management System. Procedia Computer Science Volume 168, pp. 105-111.

[6] Chen rongmin (2017): Study on the Management Strategy of students coming to China from countries along "The Belt and Road", China Higher Education, No. Z3, pp. 69-71.

[7] Marcos Mouriño-García, Roberto Pérez-Rodríguez, Luis Anido-Rifón, Manuel J. Fernández-Iglesias, Víctor M. Darriba-Bilbao (2018). Cross-repository aggregation of educational resources. Computers \& Education Volume 117, pp. 31-49.

[8] Yang, F. G, Jing, Z. Meng, Chao, J. G, Jing, L. (2012). Construction of the Practice Teaching System for "School-enterprise Cooperation" in Agricultural Specialty of College under New Situation Procedia Environmental Sciences Volume 12, Part B, pp. 1274-1279, 2012.

[9] Xu, L. (2017). The Opportunities and Challenges of the "Belt and Road" Initiative That the Poor Minority Students in Western Colleges and Universities Face. Education and Teaching Forum, 48, 48-49. 
[10] Yang, J. (2018). The Opportunities and Challenges of "the Belt and the Road" to College Education in China. Education Teaching Forum, 1, 213-214.

[11] Isabel Estrada, Dries Faems, Natalia Martin Cruz, Pilar Perez Santana. (2016). The role of interpartner dissimilarities in Industry-University alliances: Insights from a comparative case study Research Policy. Volume 45, Issue 10. pp. 2008-2022, December 2016.

[12] Anna Kartashova, Tatiana Shirko, gor Khomenko, Ludmila Naumova. (2015). Educational Activity of National Research Universities as a Basis for Integration of Science, Education and Industry in Regional Research and Educational Complexes. Procedia-Social and Behavioral Sciences. Volume 2145, pp. 619-627.
[13] Cui, Y. Z. (2019). Opportunities and Challenges Faced by Ideological and Political Work in Tibetan Colleges and Universities under the Background of "the Belt and Road" Initiative. Chinese Journal of Multimedia and Network Teaching (Early Issue), 4, 207-208.

[14] Liu, Q. (2018). Challenges and Countermeasures for Foreign Exchanges and Cooperation of western Colleges and Universities under the Background of the "Belt and Road" Initiative. Chongqing Higher Education Research, 1, 12-19.

[15] Liu, G. (2016). Analysis of the Development Opportunities for Western colleges and Universities under the Background of the "Belt and Road" Initiative. Journal of Higher Education, 10, 21-22. 